\title{
A contribuição do livro de Jorge Grespan para a formação de um pensamento crítico sobre as cidades
}

The contribution of Jorge Grespan's book to the formation of critical thinking about the cities.

La contribución del libro de Jorge Grespan a la formación de un pensamiento crítico sobre las ciudades.

La contribution du livre de Jorge Grespan à la formation d'une pensée critique sur les villes.

\section{Júlio de Campos Andrade Lamparelli}

\section{(2) OpenEdition}

\section{Journals}

\section{Edição electrónica}

URL: https://journals.openedition.org/espacoeconomia/18698

DOI: 10.4000/espacoeconomia.18698

ISSN: 2317-7837

\section{Editora}

Núcleo de Pesquisa Espaço \& Economia

\section{Refêrencia eletrónica}

Júlio de Campos Andrade Lamparelli, «A contribuição do livro de Jorge Grespan para a formação de um pensamento crítico sobre as cidades», Espaço e Economia [Online], 21 | 2021, posto online no dia 17 junho 2021, consultado o 17 julho 2021. URL: http://journals.openedition.org/espacoeconomia/ 18698 ; DOI: https://doi.org/10.4000/espacoeconomia.18698

Este documento foi criado de forma automática no dia 17 julho 2021.

\section{(c) (i) (2) (2)}

Espaço e Economia - Revista brasileira de geografia econômica est mise à disposition selon les termes de la licence Creative Commons Attribution - Pas d'Utilisation Commerciale - Partage dans les Mêmes Conditions 4.0 International. 


\section{A contribuição do livro de Jorge Grespan para a formação de um pensamento crítico sobre as cidades}

The contribution of Jorge Grespan's book to the formation of critical thinking about the cities.

La contribución del libro de Jorge Grespan a la formación de un pensamiento crítico sobre las ciudades.

La contribution du livre de Jorge Grespan à la formation d'une pensée critique sur les villes.

Júlio de Campos Andrade Lamparelli 


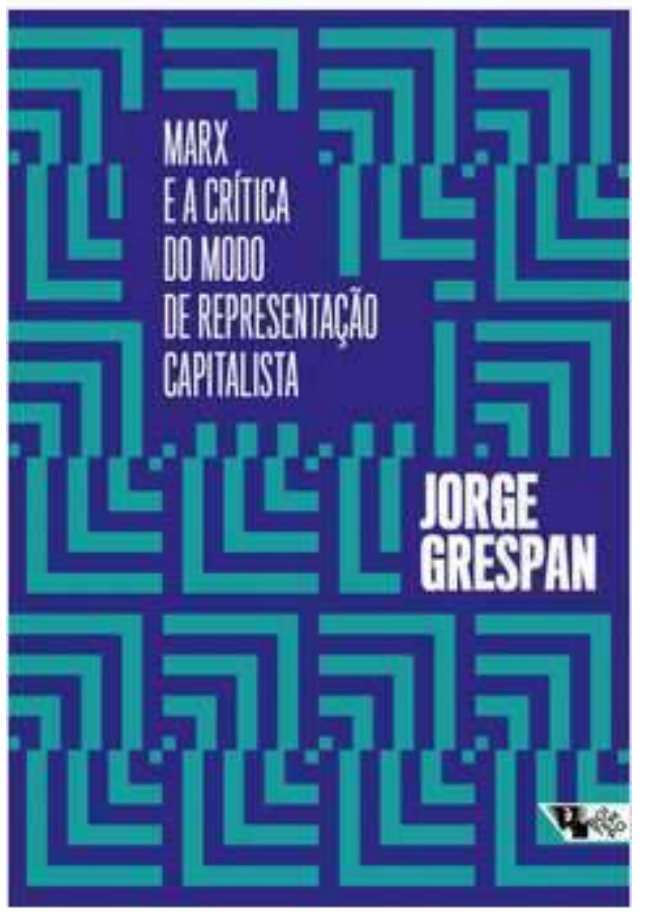

GRESPAN, Jorge. Marx e a crítica do modo de representação capitalista. Boitempo: São Paulo, 2019.

\section{A contribuição do livro de Jorge Grespan para a formação de um pensamento crítico sobre as cidades ${ }^{1}$.}

1 Em seu novo livro, Marx e a crítica do modo de representação capitalista, Jorge Grespan propõe ler a obra de Marx a partir de um ângulo pouco usual. Grosso modo, o ímpeto original está na tese de que, articulada com a crítica de Marx ao modo de produção capitalista estaria, também, uma crítica ao modo de representação capitalista. Ainda que de modo implícito na obra de Marx, a "crítica do modo de representação" é posta em destaque por Grespan, o que é possível mediante um minucioso estudo do autor sobre o emprego dos termos apresentação e representação ao longo dos três livros de 0 capital Darstellung e Vorstellung, respectivamente.

2 Em suma, interessa a Grespan ressaltar a seguinte relação: se, por um lado, o movimento das formas sociais do capital - mercadoria, dinheiro, lucro, juros etc. apresenta a riqueza produzida pelo trabalho fora do trabalho, engendrando uma miríade de formas cada vez mais descoladas da produção da mais-valia; por outro lado, essas formas ganham autonomia, apagando os rastros da apresentação que as engendrou, bem como as contradições das quais resultaram, passando a representar a riqueza imediatamente. $\mathrm{E}$, de fato, o esquema original da apresentação que se perde em representação está dado desde o fato primordial da Economia Política: a representação 
do valor produzido pelo trabalho na mercadoria, expresso a partir da troca simples de duas mercadorias, em que uma se comporta como relativa e a outra como equivalente. Portanto, em que uma mercadoria apresenta seu valor na outra, medindo-se pela outra, ao passo que a outra passa a representar um valor que surge autonomizado tanto do trabalho, quanto da mercadoria que ele mesmo produziu - um tipo de estrutura fetichista que, explorada por Marx no primeiro capítulo de 0 capital, é o ponto de partida da jornada da autonomização. Isso posto, importa para Grespan entender a necessidade social de tal movimento, bem como a necessidade de sua crítica. Afinal, é da natureza de um modo de produção que se sustenta na exploração do tempo de trabalho socialmente necessário apresentar a riqueza como se fosse algo externo ao próprio trabalho. Pari passu ao movimento de externalização da riqueza em relação ao trabalho está, portanto, o movimento de sua representação autonomizada, tal como, diante de nossos olhos, o dinheiro representa imediatamente o valor de todas as mercadorias, bem como o capital emerge da esfera da produção como um sujeito automático, determinando de fora o destino e o rumo da sociabilidade entre os indivíduos. Bem entendido, a crítica do modo de produção também contém uma crítica do seu modo de representação: aquele estranho teatro das formas sociais - e é essa a analogia que Grespan sublinha em Marx ${ }^{2}$-; formas sociais que se encenam umas às outras, teatralizando a riqueza autonomizada sob a ribalta, passando para trás os próprios sujeitos que trabalham e produzem a riqueza, escondidos por detrás das coxias.

3 Alocando-se sob tal perspectiva, quem ler Marx e a crítica... acompanhará ao longo do livro os diferentes momentos do referido "modo de representação", em escala ascendente de descolamento e autonomização das formas sociais em relação ao seu conteúdo: o trabalho abstrato, a substância do valor ${ }^{3}$. Eis que o movimento segue uma só direção, depreendido da exposição que Marx faz da distribuição da mais-valia entre as classes proprietárias, o tema do Livro III de $O$ capital: já sob interpretação de Grespan, portanto, o movimento consiste no "princípio da propriedade privada" que se destaca, a cada passo, sob o pano de fundo do valor produzido pelo trabalho, radicalizando o movimento de autonomização das formas do capital em relação ao trabalho até atingir seu grau máximo. Antes de prosseguir, entretanto, é preciso dizer que a estrutura do livro é engenhosa, e não poderá ser aqui exposta com muito rigor: vale ressaltar que o livro se divide em três partes, articulando um movimento de bate-e-volta que parte do Livro III de $O$ capital, passando em um segundo momento pelo Livro I, para retornar ao Livro III de modo elevado. Por isso, nos limitamos a argumentar que o tema central do livro de Grespan está dado pelo movimento do último volume da obra de Marx, tal como ele assim o entende: o destacamento do princípio da propriedade privada sobre o princípio do valor.

4 Atravessando, primeiramente, a formação da taxa de lucro, passando pelo lucro comercial e pelos juros, o movimento de autonomização da riqueza ganha altura máxima quando adentramos o tema da renda da terra, sobretudo quando a terra é posta como mercadoria no mercado, admitindo um preço. Trata-se de um momento em que a riqueza explorada pelo capital ganha, por assim dizer, a forma de Natureza bruta, posta sob condição de monopólio privado, perdendo finalmente os últimos laços aparentes com o trabalho, agora já distante, completamente desbotado no interior da forma da renda. Ao chegar até o limite lógico das formas do valor, portanto, reposicionamos em retrospectiva os conceitos e as categorias lançadas desde o Livro I: a começar pela própria definição de mercadoria que, a esta altura, já não pode mais 
partir do pressuposto de ser "produto do trabalho" - afinal, agora é mercadoria "qualquer coisa que seja monopolizável e vendável no mercado" ${ }^{4}$, inclusive o ar e os campos virgens.

5 Naturalmente, isso não significa um "cancelamento" do Livro I, tampouco uma anulação dos conceitos basilares de "valor" e de "mais-valia". Pelo contrário - e aí está a sagacidade da leitura de Grespan -, a negação aparente do valor na forma da renda da terra ou de seu preço significa, contraditoriamente, sua própria conclusão, e não uma contravenção excepcional a ser anotada às margens da teoria crítica. Em outras palavras: é o próprio movimento necessário e contraditório do capital e de suas formas que desagua em uma aparência e em uma representação da riqueza completamente dissociada do trabalho e, portanto, "enlouquecida", "irracional" ou "absurda", como costuma dizer Marx. Vale lembrar, contudo, que a contravenção formal da riqueza, que quer criar um conteúdo autônomo a partir de si, ou seja, a partir da propriedade privada pura e simples, está inscrita e determinada pelo próprio conteúdo que ela esconde: o valor criado pelo trabalho - que, por sua vez, não custa dizer, pressupõe a propriedade privada. Isso porque o valor, como conteúdo oculto das formas da riqueza capitalista, é ele mesmo o núcleo da negação do trabalho - que ele torna abstrato, subordinando-o à tautologia vazia e abstrata da valorização do valor. Por isso, como contradição semovente, o valor só pode se manifestar negando a si mesmo, engendrando formas que o negam e que também o abstraem, isto é, que o "esquecem". Pela sua própria natureza, e não por desvio de rota, por conseguinte, as formas do capital se esquecem de sua origem e de seu conteúdo, formando um mundo no qual a riqueza produzida pelo trabalho representa-se a si mesma fora do trabalho, como se brotasse das próprias coisas, das próprias naturezas, desde que estejam dispostas na esfera do consumo e recobertas pelo sistema de preços. Quando a terra é posta como mercadoria, portanto, finalizando a exposição de Marx em 0 capital, apenas expõe-se e radicaliza-se o princípio imanente do modo de representação capitalista, que por sua vez está presente desde a mercadoria mais ordinária.

6 Feito aqui o resumo da ópera, podemos agora adentrar o segundo momento deste texto: a contribuição do livro de Jorge Grespan para a formação de um pensamento crítico sobre nossas cidades. É que, ao posicionar os temas do Livro III à guisa de conclusão dos temas lançados no Livro I, entendendo-os como resultados das próprias contradições internas à forma-mercadoria - a célula elementar da riqueza burguesa - Grespan é capaz de revelar a centralidade fundante daqueles temas para a obra de Marx de modo geral - temas que, não obstante, foram comumente escanteados pela tradição crítica. Tradição que, não raras vezes, relegou o Livro III à condição de mero rascunho. Sofreu especial desprezo, nesse sentido, o tema da renda da terra, fazendo com que os que assim argumentaram tenham deixado passar batido nada mais que o "ponto final" da obra dedicada à crítica da Economia Política. E quem ler Marx e a crítica... tomará conta do prejuízo. Adiante, tendo em vista que o desprezo pelo tema da renda da terra teve um capítulo especial para os assuntos urbanos, e que não mais de um discípulo de Marx decretou a marginalidade do assunto no que tange à "crítica da Economia Política do espaço" - como chamam alguns -; nos permitimos orientar as descobertas de Grespan para uma nova direção, atritando com alguns consensos que foram sedimentados, sobretudo, no campo do "urbanismo crítico" - evidentemente, o título é improvisado. Partindo do texto de Grespan, eis a nossa deixa:

Embora o Livro III se refira quase sempre apenas à agricultura, que Marx supõe

dominada pelo modo de produção capitalista, o problema da renda a ultrapassa, 
expondo o elemento central da divisão do mais-valor nas considerações feitas aqui e ali por ele a respeito da propriedade de recursos naturais ou do solo urbano. É de onde se pode partir para ampliar o conceito e estendê-lo a temas contemporâneos, como os relativos ao efeito das patentes, das marcas e do chamado trabalho 'imaterial' (GRESPAN, 2019, p.71. grifo meu).

7 A passagem nos dá dimensão do peso que a propriedade privada assume para os assuntos contemporâneos, na medida em que determina a distribuição do valor produzido pelo trabalho entre as classes proprietárias: classes proprietárias que se veem, cada vez mais, prostradas a passos de distância da esfera produtiva. Distribuição que, por seu turno, nos termos da exposição categorial, atinge seu nível mais "arbitrário" no caso da propriedade privada da terra, não nos deixando esquecer nunca que a Acumulação Primitiva não só não é coisa passado, como é cada vez mais coisa do presente - ou não é isso que indica a atual predominância financeira, avizinhando como nunca os donos do dinheiro aos donos da terra? Vemos, enfim, que se esse assunto é indispensável para se pensar nossas cidades, ele é ao mesmo tempo o eixo para se pensar as práticas cada vez mais primitivas de nosso "capitalismo avançado". O que, inversamente, atesta também a centralidade da cidade - sob a rubrica do "solo urbano" - para os assuntos do presente, sobretudo quando admitimos que ela é um dos alvos favoritos dos chamados rent-seekings, e que não por acaso estão sempre com um pé nos negócios imobiliários. Em face de tais constatações, que mostram as afinidades eletivas entre as práticas espoliativas do capitalismo contemporâneo - elevando a violência da propriedade privada à enésima potência - com aquilo que sempre foi know-how no meio imobiliário - a propriedade privada da terra como baluarte da acumulação -; não podemos, então, descartar os temas do Livro III a partir de conclusões apressadas, sob o risco de nos vermos desapercebidos diante do movimento real da riqueza e de suas formas no chamado "espaço urbano".

8 A título de exemplo, temos em mente duas "conclusões apressadas": primeiro, a de que a "renda da terra" é um erro conceitual derivado de uma intriga política do passado (DEÁK, 2001, p.56), e que por isso deveria ser superada pela "Economia política do espaço"; em segundo lugar, a conclusão de que a "renda da terra envelheceu" porque, no meio imobiliário, ninguém toca mais no assunto (VILLAÇA, 1985, p.10). Duas conclusões que foram tiradas na Faculdade de Arquitetura e Urbanismo da Universidade de São Paulo há pelo menos trinta anos atrás, e que desde então decretaram a obsolescência do tema para os assuntos urbanos. Curiosamente, a segunda conclusão - de que não há renda da terra porque os agentes imediatos do comércio assim decidiram - também deve esbarrar com os temas do livro de Grespan, embora agora sobre outra perspectiva. Quer dizer, é na terceira parte de Marx e a crítica... que o autor define as "representações subjetivas" que os agentes privados assumem diante da superfície da distribuição - superfície que, no rigor de seu "modo de representação", só pode ocultar a origem do valor e apresentá-la de modo autonomizado, como vimos. Isto é, "os objetos da propriedade característicos de cada classe de agentes sociais 'aparecem' como suas respectivas fontes de rendimento (...) de modo a projetar o âmbito da distribuição do valor para o de sua produção" (GRESPAN, 2019, p. 240. grifo meu). Um caso que se torna acirrado, novamente, para os proprietários privados da terra, que assistem sua riqueza brotar magicamente das qualidades do solo, sempre em condição de monopólio privado, ao passo que seu preço é determinado no mercado. E é assim mesmo que, no meio imobiliário, todos falam que o que tem "mais valia" em um edifício é a sua localização, parecendo derivar daí a origem da riqueza que 
arrebatam no bolso - esquecendo-se que em larga medida ela deriva do trabalho explorado na própria construção daqueles edifícios, e que não por acaso se situam em um dos setores produtivos do capital que apresenta a menor composição orgânica, isto é, a maior quantidade de mão de obra empregada, proporcionalmente falando. Ora, para a teoria que se quer crítica, não se pode tomar o que se diz no meio imobiliário ao pé da letra.

9 Pelo contrário, o diz-que-diz-que dos agentes imediatos do comércio, colado que está no modo de representação que eles operam, deve ser posto sob o crivo de uma cautelosa reconstituição crítica, preocupada em atinar com seu lado esquecido, nitidamente negativo, soterrado pela cruzada de esquecimentos sociais presente em cada forma de riqueza, sobretudo em relação àquela forma social que Marx considerou ser à primeira vista absurda - o "valor da terra", que os agentes passam a atribuir em função de seu preço, fundando um "valor" prático e operacional completamente apartado de sua verdadeira origem. Alerta-nos Grespan, é esse o papel da crítica: demonstrar o fundo falso da representação do capital, que aparece como aquele que cria a si mesmo, reconduzindo-o de modo constrangedor ao cadafalso do trabalho (Idem, p.178 e p.295). E, de fato, é essa falsa pretensão de sujeito autoformador que subsiste na fórmula mais sedimentada pelo senso comum, e que as teorias urbanas fizeram pouco caso ao tomar de barato: a chamada "valorização imobiliária", que por sua vez identifica imediatamente os preços oscilantes de um imóvel a um "valor" criado por circunstâncias especiais de mercado - como, por exemplo, a localização de um determinado edifício.

Dito isso, é natural que o pessoal do meio imobiliário prefira ficar na "superfície" da produção, onde, como diz Marx, resgatado por Grespan, devem se sentir "como um peixe na água", passando a "medir valores de uso em preços" (Idem, p. 265), sem entrar no mérito de temas que possam causar maiores constrangimentos ao capital, sobretudo em sua pretensão de se autonomizar do trabalho. o problema, contudo, é quando a teoria, que se assume "crítica", passa a adotar tal perspectiva de "superfície", comportando-se, ela sim, como um peixe fora d'água, passando ao largo do tema da renda da terra e da exploração do trabalho, repisando mais uma vez o senso comum. Bom, talvez não tivesse assim feito a teoria, há trinta anos atrás, na FAUUSP, se o livro de Grespan datasse daqueles tempos, pedindo aos críticos um cuidado especial diante da esfera da distribuição e do consumo, uma vez que lá se oculta e se inverte a substância da riqueza, representando-a de modo autônomo no preço da mercadoria. Isto é, para os "assuntos urbanos", que têm a propriedade privada da terra como assunto do dia-a-dia, é indispensável o nível redobrado de cautela diante das formas da riqueza capitalista - a saber, o preço dos imóveis -, bem como é imprescindível compreender como se dá o processo de autonomização das formas sociais em relação ao trabalho, caso a teoria não queira cair no engodo do capital. Como recomenda Grespan, portanto, a teoria deve tomar a devida distância em relação ao "modo de representação" do capital e de suas "figurações", percebendo, finalmente, o seu lado negativo: a multidão de operários posta para trabalhar todos dias, faça chuva ou faça sol.

11 Direcionando, portanto, as descobertas de Grespan para a leitura dos "escritos da casa" - claro, a FAUUSP, no caso - aluguemos um pouco mais a teoria de Villaça, agora jogada à sua luz. É possível perceber, mais adiante, que a "teoria das localizações" e da "segregação urbana" de Villaça, erguida sob esfera do consumo, acaba operando a 
hipostasia da esfera da circulação de mercadorias, decretando a existência de um valor que não é a mais-valia extraída na produção. 0 valor das localizações, que é a hipótese central daquele autor, é imediatamente derivado do preço da terra, tal como se apresenta na "superfície". Isto é, conforme aprende-se com Grespan, Villaça se torna refém das formas autônomas que representam o valor criado pelo trabalho - movimento que é capitaneado pelo peso ascendente que a propriedade privada assume na esfera da distribuição. Sem reconstituir os termos entre propriedade privada e valor, contudo, a teoria sucumbe diante do fetichismo das formas que tem diante de si. Também vale destacar, nesse domínio, como a bandeira da "justiça social" erguida por Villaça, uma vez que está trancafiada na esfera da distribuição e do consumo, acaba fadada a perseguir o lema da igualdade jurídica entre proprietários, ignorando seu fundamento oculto: a desigualdade entre proprietários dos meios de produção e proprietários da força de trabalho - outro tema elaborado por Grespan, e que ganha contornos especiais em suas considerações sobre a crítica à teoria do direito que Marx encomenda a Hegel ${ }^{5}$. Em suma, entende-se que a teoria de Villaça é uma teoria que habita exclusivamente a esfera da circulação de mercadorias, colhendo daí toda sorte de ilusões e inversões de superfície. Não só isso, está aí um posicionamento que marcou, ademais, a postura progressista de nossos arquitetos e urbanistas diante das cidades brasileiras, no afã louvável de consertar uma cidade desigual por meio de políticas distributivistas sem combater, contudo, a fonte mesma da desigualdade, e que está escondida na esfera da produção: a exploração do trabalho. Afinal, é sabido como toda uma geração de intelectuais trabalhou no sentido de restringir o estudo do espaço urbano ao nível da "reprodução da força de trabalho" - e talvez o livro de Grespan seja capaz de nos dar, trinta anos depois, o tamanho do equívoco.

12 Feita a digressão urbanística, damo-nos a permissão de fazer uma pequena proposta diante da obra de Grespan. Se é um ponto forte de seu livro expor o peso que a propriedade privada assume no movimento do capital e suas formas, lançando nova luz para a discussão da renda da terra, resta, assim, dar continuidade à descoberta: rebater o princípio da propriedade privada novamente para a esfera da produção de valor propriamente dita, da qual ela havia se descolado. Quer dizer, terminada a representação fetichista do capital, expondo a pretensa autonomização da forma social a partir do princípio da propriedade privada - o ponto em que nos deixa Grespan ao fim de sua obra - falta o próximo passo: perceber como a propriedade privada, já autonomizada, passa a determinar, por sua vez, a esfera da produção. Pois esse rebatimento da propriedade privada em relação ao trabalho é especialmente importante para se pensar a formação da renda dos terrenos dedicados para a construção civil e, de modo mais geral, à produção do espaço urbano. 0 "rebatimento" de que estamos falando diz respeito às considerações de Marx sobre a "renda absoluta", as quais deixam entender que, embora o "preço da terra" seja uma representação vazia - forma sem conteúdo - por detrás dele mobiliza-se, de fato, muito mais trabalho do que o "normal". Trata-se da baixa composição orgânica do capital nos setores em que impera a propriedade privada da terra; uma determinação que não decorre de fatores, por assim dizer, culturais, mas sobretudo do próprio efeito econômico que a propriedade privada exerce sobre a produção. Marx diz, portanto, que nesse caso os produtos "serão sempre vendidos por um preço de monopólio, não porque seu preço esteja acima de seu valor, mas por ser igual a seu valor ou por estar abaixo deste, estando, contudo, acima de seu preço de produção" (MARX, 1983, p.228-9 [1894], grifo meu). Ironicamente, é naquela esfera da produção em que o princípio da propriedade privada 
ganha seu maior destaque - portanto, onde o seu peso cai como uma guilhotina na determinação do preço das mercadorias - que há, contudo, a maior quantidade de trabalho sendo mobilizado, e na qual as mercadorias estão, em suma, "encharcadas" de valor. Haja contradição. É preciso, frente à complexidade do movimento, afastar-se um pouco do exemplo do preço do "vinho caro", tão utilizado por Grespan - exemplo no qual, pelo contrário, é o "preço de monopólio que gera a renda", encarecendo a mercadoria acima de seu valor. Aceitando, portanto, o argumento de que o tema da renda da terra é fundamental para se pensar o movimento do capital no mundo contemporâneo, é preciso ainda não se esquecer do segundo giro que dá a propriedade privada no sentido de determinar, retroativamente, o trabalho que produz valor, muitas vezes elevando a níveis extraordinários a quantidade de trabalho comandada pelo capital, como não deixa mentir o caso da construção civil.

Abre-se, então, um problema para o pensamento crítico: enquanto o capital dá voltas ao céu do fetichismo e da autonomização, as cidades se transformaram ao mesmo tempo em um enorme canteiro de obras. Evitando que o exemplo do "vinho caro" se torne absoluto - sem negar, claro, sua pertinência - é preciso escapar da "especulação fácil sobre a especulação" que geralmente domina as discussões sobre o espaço urbano (OLIVEIRA, 1979, p.14), desanuviando o caminho para se compreender sua relação com o processo de exploração do trabalho. Tudo ainda mais dramático, do ponto de vista do capitalismo contemporâneo, quando se leva em conta as crescentes revoluções tecnológicas, que de fato só fazem eliminar mais trabalho do seio da produção, enquanto uma ordem considerável de mão de obra é mobilizada por detrás dos tapumes e por dentre guindastes. Com efeito, a visão reveladora do trabalho no canteiro de obras atualiza a constatação: "Para além do palco onde se encena a investidura do capital em 'sujeito' central da sociedade, descortina-se a atividades dos bastidores, com todo um maquinismo de alçapões, gruas, adereços, luzes e fumaças" (GRESPAN, 2019, p. 137). Pois bem: no que tange à "produção do espaço", ainda resta muita gente nas gruas. E, não obstante, o pensamento crítico da chamada Economia Política do Espaço se afasta, por conta e risco, dos bastidores do trabalho rumo ao urbano ${ }^{6}$, deixando passar nada menos que a grande contradição de nosso tempo: a sobrevida do trabalho no capitalismo avançado. Para acessar, contudo, os "bastidores privados da cena pública" (Idem, p. 146), local em que se arranca o curtume, será preciso retirar-se brevemente do estande de vendas imobiliário - tarefa que pode custar a etiqueta e o decoro do "urbanismo crítico", que hoje se "sente em casa" na superfície da distribuição e do consumo (Idem, p. 265), preocupado demais em solver problemas de demanda e do chamado déficit habitacional.

\section{BIBLIOGRAFIA}

DEÁK, Csaba. À busca das categorias de produção do espaço. São Paulo, Tese de Livre docência em Arquitetura e Urbanismo. Departamento de Projeto da Faculdade de Arquitetura e Urbanismo da Universidade de São Paulo, 206p., 2001. 
GRESPAN, Jorge. “As formas da mais-valia: concorrência e distribuição no Livro III de O capital”. Crítica Marxista, n.33, Campinas, pp.9-30, 2011.

GRESPAN, Jorge. Marx e a crítica do modo de representação capitalista. Boitempo: São Paulo, 2019.

HARVEY, David. "O trabalho, o capital e o conflito de classes em torno do ambiente construído nas sociedades capitalistas avançadas”. Tradução de Flávio Villaça. Espaço e Debates, n.6, São Paulo, jun/set, pp. 6-35, 1982 [1976].

MARX, Karl. O capital: crítica da economia política. Livro III: o processo global de produção capitalista. Tomo II. São Paulo: Abril Cultural, 1983 [1894].

OLIVEIRA, Francisco de. "Prefácio". In: MARICATO, Ermínia. (org.). A produção capitalista da casa (e da cidade) no Brasil industrial. São Paulo: Alfa-ômega, pp. 13-20, 1979.

VILLAÇA, Flávio. “A Terra como Capital (ou a Terra-Localização)”. Espaço \& Debates, ed. 16, pp. 5-14, 1985.

\section{NOTAS}

1. Um produto realizado com apoio da FAPESP, por meio do financiamento relacionado ao processo no 2018/11270-2, Fundação de Amparo à Pesquisa do Estado de São Paulo (FAPESP).

2. Ver, a título de exemplo, GRESPAN, 2019, pp. 12-13 ou p.239.

3. Sobre o problema da "substância", ver sobretudo: Idem, p.87-8 e p.177.

4. Quanto à redefinição do conceito de mercadoria, ver: Idem, p.37, p.211, p.219 e p.232. Já no que tange ao "último momento" do valor identificado com a renda da terra, o movimento pode ser seguido no capítulo 2, intitulado "Equalização", também exposto no artigo "As formas da maisvalia: concorrência e distribuição no Livro III de O capital” (GRESPAN, 2011).

5. Como se pode ver ao fim do capítulo 6 de Marx e a crítica...

6. Posto que o urbano foi decididamente restringido à dimensão do "viver" em oposição ao "trabalhar", como ficou consagrado em um texto já antigo de David Harvey (1982) [1976].

\section{RESUMOS}

Este trabalho tem por objetivo enfatizar as descobertas do último livro de Jorge Grespan, Marx e a crítica do modo de representação capitalista, direcionando-as para os assuntos urbanos - isto é, para a produção do espaço e das cidades. Com efeito, este texto pode ser dividido em duas partes: uma primeira, em que ganham destaque os temas de interesse no livro de Grespan; uma segunda, em que orientamos os referidos temas em direção a algumas teorias já sedimentadas da chamada "Economia Política do Espaço" - em especial, em direção à teoria do valor das localizações, de Flávio Villaça. Em suma, interessa notar a centralidade que o tema da renda da terra, antecedida por outros temas do Livro III de 0 capital, assume na argumentação de Grespan, sobretudo quando ele é posto no eixo da crítica do modo de representação capitalista - levando ao extremo a contradição posta entre princípio de propriedade privada e princípio do valor produzido pelo trabalho. 
In this work we aim to underline some scientific findings which are contained in Jorge Grespan's new book, Marx e a crítica do modo de representação capitalista, and to bear them in mind when addressing "urban subjects"- namely, the production of space and of the cities. Therefore, this text can be divided in two parts: the first one, in which topics of interest in Grespan's book come to the fore; the second, in which these topics are directed towards what became known as "Political economy of space" - particularly, towards Flávio Villaça's location value theory. In a nutshell, it is worth noting the centrality that the "land rent" issue, preceded by other themes of the third book of Marx's Capital, acquired in Grespan's argument, mainly when it is placed in the axis of the "criticism of the capitalist mode of representation", thus taking to the extreme the contradiction between the principle of private property and the principle of the value produced by the work.

Este trabajo tiene como objetivo enfatizar las descubiertas presentes en el último libro de Jorge Grespan, Marx e a crítica do modo de representação capitalista, conduciéndolas a los asuntos urbanos - es decir, a la producción del espacio y de las ciudades. De hecho, podemos dividir este texto en dos partes: una primera, en la que destacamos los temas de interés del libro de Grespan; y una segunda, dedicada a orientarlos hacia algunas teorías ya establecidas en la denominada "Economía Política del Espacio" - en especial, hacia la teoría del valor de las localizaciones de Flávio Villaça. En síntesis, nos interesa señalar la centralidad que el tema de la renta de la tierra, que siegue otros temas del Libro III de El capital, asume en la argumentación de Grespan, especialmente cuando se coloca en el eje de la crítica del modo capitalista de representación llevando al extremo la contradicción entre el principio de la propiedad privada y el principio del valor producido por lo trabajo.

Ce travail vise à mettre en evidence les découvertes contenues dans le dernier livre de Jorge Grespan, Marx e a crítica do modo de representação capitaslita, en les orientant vers ce que nous pourrions appeler "sujet urbaines" - c'est-à-dire, vers la production de l'espace et de les villes. En effet, ce texte pourrait être divisé en deux parties distinctes: une première, dans laquelle nous mettons en évidence les sujets d'intérêt présents dans le livre de Grespan; une deuxième partie, dans laquelle nous orientons ces thèmes vers certaines théories déjà consolidées de la soi-disant "Economie politique de l'espace" - en particulier, vers la théorie de Flávio Villaça sur la valeur de la localisation. En bref, il est important de se rendre compte que le thème de la rente foncière gagne une place central sur la critique du mode capitaliste de représentation, ainsi qu'avec les autres thèmes contenues dans le troisième livre du Capital de Marx - comme Grespan nous apprend, bien sur, à savoir: en prenant à l'extrême la contradiction entre le principe de la propriété privée et le principe de valeur produit par le travail.

\section{ÍNDICE}

Palavras-chave: Economia Política, teoria crítica, espaço urbano, renda da terra, planejamento urbano.

Mots-clés: Économie Politique, théorie critique, espace urbain, rente foncière, aménagement du territoire.

Palabras claves: Economía Política, teoría crítica, espacio urbano, renta de la tierra, planeamiento urbano.

Keywords: Political economy, critical theory, urban space, land rent, urban planning. 
AUTOR

JÚLIO DE CAMPOS ANDRADE LAMPARELLI

Universidade de São Paulo, Faculdade de Arquitetura e Urbanismo.

E-mail: julio.lamparelli@usp.br; juliolampa@gmail.com. 